\title{
A PRÁTICA PEDAgógIGA dAS PROFESSORAS dA EDUCAÇÃO INFANTIL EM RELAÇÃO ÀS MÚSICAS DE MÍDIA
}

\section{THE PEDAGOGICAL PRACTICE OF PRE-SCHOOL TEACHERS IN RELATION TO MEDIA MUSICS}

\author{
Carolina Duminelli Frigo ${ }^{1}$ \\ Édina Regina Baumer ${ }^{2}$
}

RESUMO: O presente artigo apresenta como objetivo geral analisar se as professoras da Educação Infantil utilizam das músicas de mídia em sala de aula. E a partir disso desmembraram-se os objetivos específicos que foram: compreender a importância da música para o desenvolvimento cognitivo da criança; refletir sobre as músicas de mídia e outros gêneros musicais trabalhadas dentro da sala de aula; identificar diferentes possibilidades de trabalhar a música na escola; verificar se as professoras utilizam CDS e DVDS apenas para entretenimento, ou se é proposto cantar com gestos e outras expressões corporais. A pesquisa, de natureza básica, com abordagem qualitativa, quanto ao procedimento técnico se utilizou da pesquisa de campo, por meio de um questionário em uma escola particular, na região de Criciúma-SC, com sete professoras da educação infantil. Foi possível concluir que algumas participantes utilizam a música para momentos de descontração e para auxiliá-las nos projetos pedagógicos. Elas reconhecem a importância que a música tem na educação dos seus alunos como processo de aprendizagem, porém, algumas apontaram que nem todas as práticas estão realmente alcançando o objetivo de aprendizagem. Podemos destacar também que o CD e DVD já estão sendo pouco usados em sala de aula e que os meios tecnológicos mais avançados estão mais em uso pelas professoras. Por fim, podemos dizer que a música é um elemento auxiliador para a formação das pessoas e nesse sentido, a música de mídia, mediada pelo professor de maneira significativa, pode sim contribuir para aprendizagem do educando, assim, como citado acima, sobre o desenvolvimento da sensibilidade, do senso rítmico, da criatividade, da escuta musical, da expressão corporal entre outros, desde a Educação Infantil.

PALAVRAS CHAVE: Educação Infantil. Músicas de mídia. Práticas pedagógicas.

ABSTRACT: This article presents a general objective to analyze if the teachers of Early Childhood Education use the media music in the classroom. From this, the specific objectives were: to understand the importance of music for the child's cognitive development; reflect on the music of the media and other musical genres worked within the classroom; identify

\footnotetext{
${ }^{1}$ Graduada em Pedagogia UNESC. carolinafrigo@ hotmail.com.
}

${ }^{2}$ Professora Mestre em Educação - Graduação em Pedagogia.

Saberes Pedagógicos, Criciúma, v. 4, nº1, janeiro/abril 2020.- Curso de Pedagogia- UNESC 


\section{SABERES PEDAGÓGICOS}

Revista do Curso de Graduaçāo de Pedagogia - Unesc

ISSN 2526-4559

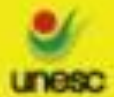

thistion

different possibilities of working music in school; check if teachers use CDS and DVDS only for entertainment, or whether it is proposed to sing with gestures and other body language. The basic research, with a qualitative approach, regarding the technical procedure was used in the field research, through a questionnaire in a private school, in the region of Criciúma-SC, with seven nursery teachers. It was possible to conclude that some participants use the music for moments of relaxation and to assist them in the pedagogical projects. They recognize the importance that music has on the education of its students as a learning process, however, some have pointed out that not all practices are really achieving the learning objective. We can also emphasize that the CD and DVD are already being used little in the classroom and that the most advanced technological means are more in use by the teachers. Finally, we can say that music is a helpful element for the formation of people and in this sense, media media, mediated by the teacher in a significant way, can rather contribute to the student's learning, as mentioned above, about development of sensibility, rhythmic sense, creativity, musical listening, corporal expression among others, from the Infantile Education

KEYWORDS: Child education. Media songs. Pedagogical practices.

\section{INTRODUÇÃO}

Ao longo da história, pensadores, filósofos, psicólogos e pedagogos já falavam sobre a importância da música. A música era usada para rituais, como casamentos, nascimento ou morte. Atualmente a música é vista como um arranjo ou uma combinação de som. Porém a música dentro da sala de aula vai muito além do cantar e tocar (ANDRADE, 2012).

Podemos destacar que trabalhar a música dentro da sala de aula é dar acesso ao processo de educação da criança, ou seja, conduzir sabendo das contribuições que a música pode trazer, de forma que não seja apenas uma recreação, mas sim, um momento de aprendizado, o qual possa estimular o desenvolvimento de cada criança, como por exemplo, sua criatividade, o senso rítmico, imaginação e concentração.

A música na educação brasileira ainda é vista como uma forma de entretenimento, um recurso usado apenas para complementar projetos. A educação é essencial para a evolução do ser humano e a escola hoje, poderia rever a formação do professor, ou seja, conseguir refletir melhor sobre a qualidade do processo de formação, o qual garantira a qualidade de ensino. Uma dos fatores para essa melhoria da qualidade pode ser a linguagem musical.

Saberes Pedagógicos, Criciúma, v. 4, nº 1, janeiro/abril 2020.- Curso de Pedagogia- UNESC 


\section{SABERES PEDAGÓGICOS}

Revista do Curso de Graduaçūo de Pedagogia - Unesc

ISSN 2526-4559

Algumas questões que podemos citar para uma boa qualidade de planejamento para as aulas de música, são as canções, jogos, danças, os exercícios de movimento, relaxamento, prática instrumental, audição e também podemos destacar que quando apresentamos à criança as noções básicas de ritmo e melodia, ela pode estabelecer relações dessas noções com o seu mundo lúdico.

Também é preciso refletir sobre as músicas de mídia reproduzidas dentro da sala de aula, músicas por muitas vezes com frases inapropriadas para as crianças. Podemos sim colocar diferentes gêneros musicais. Entretanto faz-se necessário pesquisar, ouvir que tipo de mensagem a música está trazendo. A música torna o ambiente escolar mais alegre e próspero para a formação educacional, possui aspectos que trabalham com a capacidade racional e também com a emocional e com isso poderá então, contribuir para aprendizagem de cada criança.

Diante dessa reflexão sobre a música na Educação Infantil, destaca-se como problema de pesquisa: As professoras da Educação Infantil utilizam as músicas de mídia em sala de aula? E ao refletir sobre esse problema apresenta-se o objetivo geral deste estudo: Analisar se as professoras da Educação Infantil utilizam das músicas de mídia em sua sala de aula. A partir disso desmembraram-se os objetivos específicos: Compreender a importância da música para o desenvolvimento cognitivo da criança; refletir sobre as músicas de mídia e outros gêneros musicais que são trabalhados dentro da sala de aula; identificar diferentes possibilidades de trabalhar a música na escola; verificar se as professoras utilizam CDS e DVDS apenas para entretenimento, ou se é proposto cantar com gestos e outras expressões corporais.

Dessa forma a pesquisa se caracteriza como de natureza básica, que tem objetivo gerar novos conhecimentos para a ciência, sem a aplicação prática. Com uma abordagem qualitativa, propôs pesquisar as práticas docentes das professoras sobre a música de mídia. “A investigação qualitativa é uma forma de estudo da sociedade que se centra na forma como as pessoas interpretam e dão sentido às suas experiências e ao mundo em que elas vivem." (SANTOS; SANTOS, 2010, p. 42). 
Logo, elaborou-se uma escrita a partir das falas das professoras, explorando os dados coletados por meio de um questionário, concretizando assim a pesquisa de campo. Esta pesquisa foi realizada em uma escola particular, na região de Criciúma-SC, com sete professoras da Educação Infantil; quatro já formadas em Pedagogia e Magistério, e outras três em formação em Pedagogia com o término em dezembro de 2018.

O questionário contém as seguintes perguntas: 1- Em sua opinião, qual a importância da música para o desenvolvimento da criança? 2- Que tipos de música você utiliza em sala de aula? 3- Você utiliza as músicas de mídia em sala de aula? 4- Em suas aulas, é utilizado CD E DVD? Quais? E em que momentos? 5- Você acredita que a música de mídia contribui para a educação da criança? Justifique sua resposta.

\section{A MÚSICA NA EDUCAÇÃO INFANTIL}

A infância não é influenciada apenas pelas crianças, mas também pela família e pela escola. De acordo com Kuhlmann e Fernandes (2004), na antiguidade a educação era apenas voltada para os homens burgueses e só nos séculos XIX e XX, na modernidade, que passou a ser compreendido que a criança precisava viver sua infância e também passou a frequentar a escola. Mas, ainda hoje nem todas as crianças vivem sua infância, pois isso ainda depende muito do fator social e cultural.

Segundo as Diretrizes Curriculares da Educação Infantil da Rede Municipal de ensino de Criciúma- SC, a criança na sua infância, tem uma potencialidade grande de aprendizagem e desenvolvimento, e com isso, apresenta uma maior facilidade de aprender e entender, por intermédio de experiências significativas. E também, por meio da interação, das brincadeiras e da linguagem, construindo assim sua identidade (CRICIÚMA, 2016).

Dentro dos currículos escolares, encontram-se sugestões de temas em que os professores podem usar. Um desses temas, que é muito usado em sala de aula é a música, a qual pode estabelecer uma integração com as demais áreas, oportunizando a elaboração de projetos interdisciplinares. 
Segundo as Diretrizes Curriculares da Educação Infantil da Rede Municipal de Ensino de Criciúma - SC, “Com a lei n 11.769/08, a música passa a ser conteúdo obrigatório, na Educação Básica com objetivo de desenvolver a sensibilidade e a integração dos/as alunos/as e não formá-los músicos" (CRICIÚMA, 2016, p. 155).

Lino (2005) nos questiona sobre as escolas e o que elas tem feito para auxiliar no processo educativo com música, qual é a colaboração sobre a construção de conhecimento dos profissionais, pois hoje usam a música de maneira pronta, a fim de incentivar somente a reprodução. Atualmente, muitas das músicas que são tocadas em sala de aula tornaram-se um modismo cultural e a mídia é uma grande influenciadora.

Para Queiroz (2000), não existe um conceito concreto de onde veio a música, mas ela está presente em todos os campos, em todas as culturas, fazendo parte do cotidiano das pessoas. Logo é a música que mexe mais com a nossa sensibilidade, ou seja, a música nos toca mesmo quando estamos desatentos, é uma arte que instiga a sensibilidade de maneira rápida, mas a cada gênero musical temos um tipo de sensibilidade.

Queiroz (2000, p. 15) também enfatiza que "a música tem como qualidade intrínseca relaxar a sensorialidade humana, por satisfazê-la, e com isso conduz as pessoas a um estado receptivo e sensível, em especial quanto às emoções.”

A música na sala de aula pode ser uma atividade divertida, a qual ajuda na formação da identidade da pessoa, mexe com o emocional, proporciona um estar para o ambiente e pode auxiliar no desenvolvimento da coordenação motora dos educandos.

Queiroz (2000) cita dois exemplos de diferentes gêneros e diferentes sons: um deles é a percussão, com batuques fortes, e a outra, é o quarteto de cordas de mozartiano. As duas formas geram sensibilidade, porém o batuque afeta mais rapidamente o nosso lado físico, o movimento do corpo, já o quarteto de mozartiano estimula a nossa compreensão mental.

Queiroz (2000, p. 20) ainda explica que existe a música comercial, essa não tem finalidade de sensibilizar, mas passar a imagem de quem está cantando. Nos dias atuais podemos observar que esse tipo de música está bem presente principalmente nas escolas e mesmo que não estamos atentos, nossos ouvidos escutam, por conta do meio onde estamos inseridos.

Saberes Pedagógicos, Criciúma, v. 4, nº1, janeiro/abril 2020.- Curso de Pedagogia- UNESC 


\begin{abstract}
No campo popular talvez nem seja necessário apresentar a questão. São muitos e bem conhecidos os exemplos de música que é a embalagem para estimular a receptividade do público ao próprio músico. Uma música que ajuda a imagem do 'músico' a entrar em nosso imaginário. Pode-se dizer que na música comercial, o poder de sensibilização da música está a serviço de facilitar a receptividade do público à imagem do próprio artista.
\end{abstract}

Hoje, os gostos musicais que as crianças revelam nas escolas, na grande maioria, vêm de suas casas, pelo fato de que certas músicas estão muito presentes nos meios de comunicação como a televisão, o rádio, o celular. Cada meio social impõe ou propõe um diferente estilo e as crianças hoje estão inseridas nesses meios. Muitas vezes o repertório das pessoas que convivem com as crianças influenciam na formação do seu repertório musical.

\footnotetext{
Conhecer as experiências trazidas pelas crianças é fundamental, pois, tomar conhecimento do que ouvem, possibilita a ampliação do repertório de cada uma, proporcionando o desenvolvimento da sensibilidade estética, da escuta, construindo um gosto musical a partir do que ouvem e apreciam (CRICIÚMA, 2016, p. 157).
}

Nesse sentido os professores da Educação Infantil, e na educação em geral, na hora de trabalhar o tema sobre música, devem ter o cuidado na escolha da mesma, pois é preciso diferenciar os tipos de obras musicais, já que, segundo Queiroz (2000), é preciso separar os gêneros musicais e entender quais são as suas finalidades. Para o autor uma música - artística, folclórica ou popular pode ter como objetivo afetar a sensibilidade humana, ou ser uma música que está vinculada ao meio de comunicação, para apenas vender e lucrar.

Trabalhar a música em sala de aula, não significa trabalhar para tornar os alunos músicos, contudo vai proporcionar a vivência e a compreensão da linguagem musical, pois segundo Coelho, Moreira e Santos (2014, p. 46), a música pode "propiciar a abertura de canais sensoriais, facilitando a expressão de emoções, ampliando a cultura geral e contribuindo para a formação integral do ser."

Um dos objetivos que a Diretrizes Curriculares Nacionais para a Educação Infantil, de 2010, vem nos trazer para a sala de aula, é justamente sobre a interação que a música pode propiciar na Educação Infantil. O documento orienta que as experiências nesse nível de ensino, entre outras atividades, devem promover “[...] o relacionamento e a interação das crianças com diversificadas manifestações de música.” (BRASIL, 2010, p. 26).

Saberes Pedagógicos, Criciúma, v. 4, nº 1, janeiro/abril 2020.- Curso de Pedagogia- UNESC 


\section{SABERES PEDAGÓGICOS}

Revista do Curso de Graduaçāo de Pedagogia - Unesc

ISSN $2526-4559$

Segundo Lino (2009, p. 64), as crianças podem construir de maneira lúdica seu próprio conhecimento musical, ou seja, quando elas interagem com objetos sonoros do seu cotidiano, que podem estar presente dentro ou fora das composições musicais. "Assim dentro de um processo ativo e lúdico, a criança poderá construir seu conhecimento musical, quando interagir com os objetos sonoros existentes em seu contexto social.”

Lino (2009) sugere uma atividade para ser realizada com as crianças, que é pedir para que tragam de casa um objeto sonoro o qual elas gostem. A partir da imaginação do grupo, esses objetos podem se transformar em chocalhos, baterias etc. Essa ideia é uma proposta de atividade de improvisação, que propicia o desenvolvimento da percepção, da expressão e da comunicação.

A mesma autora nos traz também, que deve-se cantar para as crianças, pois nos primeiros anos ela mais ouve do que canta. Muitas crianças não entoam a música, apenas se movimentam e, com isso, aprendem sobre o ritmo, o pulso da música. Junto à criança pode-se fazer invenções de letras de maneira lúdica. "Cante para o bebê que você está educando, pois a voz humana é insubstituível em sua ternura e expressão, acarretando uma maior fluência na musicalidade infantil.” (LINO, 2009, p. 73).

De acordo com Lino (2009) para a sala de aula pode-se criar momentos musicais com os educandos, construindo um acervo musical e experimentando os instrumentos. Não apenas deixar tocar o CD ou DVD, como fundo musical, enquanto a criança está fazendo uma atividade de escrita, por exemplo.

Mas, que tenha um momento apenas para a música, pois a escola é um lugar no qual as crianças devem ter a oportunidade de diversas escutas. Escutas livres, músicas de repertório infantil, folclórico, mas também não deixando de lado o repertório adulto. Tomando todo o cuidado com as letras, como já dito, para que assim, as crianças possam conhecer diferentes expressões musicais inseridas na sociedade.

Para Assano (2000), o som do cotidiano pode ser considerado um ruído ou um som agradável aos ouvidos. Por exemplo, algumas pessoas podem achar que o som da natureza é um ruído, outras podem gostar de ouvir para relaxar. Segundo a autora, nós devemos educar nossos ouvidos, ou seja, aprender a escutar, pelo fato de que às vezes alguns

Saberes Pedagógicos, Criciúma, v. 4, nº 1, janeiro/abril 2020.- Curso de Pedagogia- UNESC 
sons nós apreciamos e outros não. Alguns sons se tornam desagradáveis ainda que não seja da vontade de escutá-lo, mas pelo fato de estar presente em nosso meio, daí vem à importância de começar a educar os ouvidos desde a infância. Assano (2000, p. 27) vem nos questionar: "Por que ao invés de somente levarmos músicas prontas, não criamos ou deixamos que as crianças também construam as suas próprias músicas?"

Lino (2009) e Queiroz (2000) também nos falam sobre os professores que levam apenas músicas prontas, para apenas reproduzir, sendo que os educandos podem construir suas próprias músicas. Através da improvisação, imitação dos sons convencionais ou do cotidiano, e com isso estimulando a imaginação da criança.

Lino (2009) enfatiza sobre a importância das crianças tocarem instrumentos musicais e ouvirem músicas para assim, desenvolver a sensibilidade, e Queiroz (2000), também nos traz sobre esta importância e com isso, o educando terá uma boa escuta.

O autor Lazzarin (2005, p. 27), vem se referir sobre as atividades pedagógicas, as de apreciação e produção da música, de mostrar diferentes gêneros e gostos musicais que existem em uma sala de aula e com isso oferecer mais espaços para a prática musical.

\begin{abstract}
No modelo multidimensional, por sua vez, a ênfase recai sobre a música como processo. Essa parece ser uma contribuição importante, na medida em que se deixa de idolatrar a genialidade da música 'séria', e se olha para a produção do estudante que vive a experiência com música. Na medida em que se deixa um pouco de lado a exigência da genialidade do produto acabado, pode-se dar espaço para outras possibilidades da experiência com música, como a da própria produção dos estudantes.
\end{abstract}

Podemos perceber que os autores, Queiroz (2000), Lino (2009) e Lazzarin (2005), nos falam sobre a escuta da música, a importância da audição, para se sensibilizar e se conectar com a música, também de se ter um espaço, um momento próprio para esta escuta. $\mathrm{E}$ a autora Beyer (2005), vem dizer que a música faz parte da vida da criança desde o quinto mês de gestação e está presente por toda a vida. Daí vem a importância de ser mostrada em sala de aula, ou seja, deixar com que as crianças, além de ouvir e sentir a música, sejam as próprias compositoras de suas músicas e criem instrumentos, interagindo no meio social, no cotidiano.

Saberes Pedagógicos, Criciúma, v. 4, nº 1, janeiro/abril 2020.- Curso de Pedagogia- UNESC 
É preciso oportunizar vários tipos de música para as crianças, pois, hoje algumas músicas de mídias inseridas na nossa sociedade têm relevância, são de qualidade e vai depender dos professores trabalharem esses produtos da mídia com conhecimento.

Também é preciso ter o cuidado ao usar os meios tecnológicos como o CD e DVD, pois, às vezes estamos apenas nos deixando dominar pela música comercial. Professores devem fazer com que as crianças através da música se emocionem e se conectem, assim, ativando a imaginação.

Diante de toda essa importância da música para a criança, veio a preocupação sobre como as professoras da Educação Infantil se utilizam das músicas de mídia em sua sala de aula, especificamente em uma escola da nossa região. Destaco que ao citar 'música de mídia' refiro-me aos conteúdos musicais que são veiculados pelos meios de comunicação de massa, como a televisão e a internet. ${ }^{3}$

\section{METODOLOGIA, APRESENTAÇÃO E ANÁLISE DE DADOS}

Após efetuar a etapa do referencial teórico e aplicar os questionários com as professoras, partiu-se então para o processo de análise dos dados coletados. Neste espaço serão apresentados os dados da pesquisa realizada com as professoras da Educação Infantil, representadas como P1, P2, P3, P4, P5, P6 e P7. A primeira questão foi sobre a opinião de cada uma sobre a importância da música para o desenvolvimento da criança.

As participantes reafirmaram a importância da música sendo que duas delas reforçaram que esta vem desde o ventre da mãe (P4 e P5). As professoras P6 e P2 ressaltaram como importante para o desenvolvimento da imaginação. Cinco professoras destacaram a questão relacionada ao movimento, como por exemplo, desenvolvimento psicomotor, coordenação motora e o deslocamento no espaço (P1, P3, P4, P5, P7).

Destacando a frase que as participantes afirmam sobre a importância da música vir desde o ventre da mãe, podemos aqui citar a autora Beyer (2005, p. 97) que afirma: "Deparamo-nos diante de uma literatura que destaca feitos surpreendentes nos bebês (ouvir e

\footnotetext{
${ }^{3}$ SUBTIL, Maria José D. Músicas, mídias e escola: relações e contradições evidenciadas por crianças e adolescentes. Educar em Revista, Curitiba, Brasil, n. 40, p. 177-194, abr./jun. 2011. Editora UFPR.

Saberes Pedagógicos, Criciúma, v. 4, nº1, janeiro/abril 2020.-Curso de Pedagogia- UNESC
} 
reconhecer música na vida intra-uterina, reconhecer a voz da mãe no parto e antes dele, perceber diferenças entre música rock e erudita, diferenciar a voz da mãe de outras vozes femininas)."

Quatro professoras se referiram ao desenvolvimento afetivo, citando a afetividade e o sentimento, (P2, P4, P6, P7). Já as participantes P2, P5, P6, P7, afirmaram que a música contribui para o processo de aprendizagem ou processo cognitivo. As professoras P1, P3 e P4 apontaram o desenvolvimento da percepção visual e auditiva. Além dessas respostas, foi citado o trabalho com o lúdico, o faz de conta, a criatividade e o desenvolvimento social, a atenção e também o desenvolvimento linguístico.

Embasado nessas afirmações, podemos citar Queiroz (2000, p. 118):

Diante de uma música melodiosa, podemos facilmente praticar este primeiro modo de percepção. Normalmente, a melodia musical incita uma reação em nós do tipo imaginativa ou fantasiada e com ela nos envolvemos em algum tipo de história sonhada que fortalece o sentimento transmitido pela música, e assim música e percepção trabalham na formação de um determinado sentimento.

Quando questionadas sobre os tipos de músicas utilizadas em sala de aula, as participantes P3, P4 e P7 mencionaram que as músicas antigas fazem parte da rotina escolar. Nessas respostas, o que parece é que as professoras não levam em conta o repertório das crianças, como também, não oportunizam que as mesmas experimentem outros gêneros musicais.

No entanto, P4, na sequência de sua resposta, afirma, assim como P1, que é importante conhecer o repertório musical das crianças. Essas professoras (P4 e P1) valorizam o interesse e possibilitam a escolha das músicas, proporcionando assim, que as crianças cantem e se expressem.

Suas falas vão de acordo com o pensamento de Lino (2009, p. 74), no que diz respeito à voz das crianças, pois, "Trabalhar com a voz é trabalhar com o corpo, uma vez que este é nosso instrumento musical por excelência.” E também a professora P3 diz que, para os momentos de 'sufoco', utiliza a famosa galinha pintadinha.

As professoras P2 e P6, mencionaram que a música tem apenas uma intenção Saberes Pedagógicos, Criciúma, v. 4, nº 1, janeiro/abril 2020.- Curso de Pedagogia- UNESC 
pedagógica, não levando em consideração as diferentes oportunidades que a música pode proporcionar, sendo estes, o movimento, sentimento, cantar, dançar, tocar, expressar-se com a voz e o corpo, entre outras experiências significativas, além disso, Lino (2009, p. 80), afirma que, "a escola é um lugar pedagógico por excelência e por essa razão é o local onde devemos oportunizar diferentes modalidades de escuta infantil."

Além desses aspectos, foram citados músicas para dançar, cantigas de rodas, músicas de caráter pedagógico, músicas para brincar, de movimentos, na contação de histórias e música infantil em diversos momentos. De acordo com Assano (2000, p. 29):

Todos os professores e professoras deveriam saber que sabem música e, a partir daí, contribuir para a formação musical das crianças, principalmente na sensibilização delas para o ouvir/compreender. Assim, poderiam formar ouvintes mais atentos que talvez 'veriam melhor com os ouvidos' os produtos musicais de baixa qualidade a que são submetidos.

Na pergunta seguinte, com relação às músicas de mídia, as professoras P2 e P7 afirmaram que não utilizam em sala de aula. P2 diz que na sua concepção, essas músicas não possuem conteúdo ou sentido e são apenas passa tempo. Entretanto Lino (2009, p. 82), vem nos dizer que se deve ter momentos de escutas em sala de aula, "momentos de audição infantil: momentos para vivenciar outras músicas (feitas para gente grande também, a fim de que as crianças possam ir conhecendo as diferentes expressões musicais desenvolvidas através das civilizações)."

As professoras P1, P3, P4 E P6, utilizam as músicas de mídia para momentos de descontração, para alguma apresentação de dança e P4 também diz que usa se estiver relacionada ao tema do projeto. E a professora $\mathrm{P} 5$, diz que sempre procura algo novo e diferente, o qual possa estimular as crianças. Destacando sobre o cuidado que deve-se ter em levar a música para sala de aula, Lino (2009, p. 68), vem explicar que:

Nesse contexto a tônica do trabalho pedagógico é possibilitar um ambiente de descoberta e revelação dos imaginários infantis, buscando a organização da forma e a conquista de outros possíveis, a partir do fazer musical - forma que, inerente à linguagem musical, deve ser estruturada no dia-a-dia da sala de aula em sua totalidade, na direção dos ilimitados infantis. Quando falo em totalidade, estou

Saberes Pedagógicos, Criciúma, v. 4, nº1, janeiro/abril 2020.- Curso de Pedagogia- UNESC 
querendo dizer que a música deve ser desenvolvida na amplitude de seu acontecer, o que inclui não somente cantar musiquinhas no dia das mães ou melodias especificas para lavar as mãos, sentar, guardar os brinquedos, mas também, principalmente, compor, improvisar, explorar o seu corpo como um instrumento musical, conhecer, manipular, classificar, registrar, identificar, escutar sons e músicas, tocar, movimentar-se no espaço, apreciar a literatura universal da música, refletir, participar de performances, enfim, produzir e pensar música.

As pesquisadas quando indagadas se utilizam CD e DVD em sala de aula, P2, P3, P5, P6 e P7, afirmam que não usam esses meios, porém em seguida colocaram que utilizam pen-drive, bluetooth e youtube, sendo que esses também são meios tecnológicos. Essas mesmas pesquisadas, dizem que usam para momentos de atividade, descontração, brincadeiras ou então para datas comemorativas como dia dos pais e dia das mães.

Contudo, as professoras P1, P4, utilizam o CD e DVD, trabalhando em conjunto com o projeto que está sendo desenvolvido. P6 diz que usa o DVD não com muita frequência, pois normalmente são colocados em sites da internet.

As professoras quando questionadas sobre acreditar que a música de mídia contribui para a educação da criança, todas as pesquisadas afirmaram que sim, contudo, elas acreditam que depende de alguns fatores, como por exemplo, segundo P7, se a música for de caráter educativo.

A participante $\mathrm{P} 4$ afirma que ama trabalhar com a música, pois, ela proporciona momentos incríveis e uma aprendizagem significativa para os alunos. A mesma pesquisada vem contribuir e dizer que a música tem fatores muito importantes, em momentos que a música envolve o sentimento, interação social e o ritmo.

A resposta da professora P5 é de grande relevância, pois vem nos dizer que a música é sim um instrumento facilitador para o desenvolvimento da criança, mas, cabe o educador saber usar as estratégias adequadas.

A participante P6, afirma que depende da questão do gênero e da qualidade da música e ainda afirma que em sua sala de aula a música de mídia está presente, pois ela faz parte da cultura e do dia a dia de seus educandos.

Com relação com a música de mídia é preciso pensar que:

O que está muitas vezes, por trás da nossa dificuldade em reconhecer o valor de Saberes Pedagógicos, Criciúma, v. 4, nº1, janeiro/abril 2020.- Curso de Pedagogia- UNESC 
determinadas manifestações musicais é a não compreensão de que música é uma estruturação do material sonoro, uma elaboração cultural, dentro de sua história. Muitas vezes assumimos uma posição etnocêntrica que nos impede a compreensão do novo, rejeitando-o simplesmente ou rotulando-o de exótico primitivo. (LAZZARIN, 2005, p. 28).

Enquanto a professora P3, respondeu que é imprescindível a música para o desenvolvimento da criança, também nos diz que a música pode e deve ser usada para somar nas atividades pedagógicas e nos momentos de descontração. Em contrapartida, a pesquisada P2, diz que é necessário filtrar as músicas que estão inseridas em nosso meio, pois as crianças estão escutando músicas de adultos e muitas das que são feitas para as crianças são um passatempo.

P2, quando questionada sobre os tipos de músicas que ela utiliza em sala de aula, afirma que usa músicas com referência aos conteúdos e campos de experiência dos projetos e também diz que usa para a ampliação da criatividade das crianças. Músicas referentes aos conteúdos/ campos de experiências dos projetos, e músicas que são base para brincadeiras, bem como para a ampliação da criatividade das crianças.

Mas, essa sua fala não vai ao encontro do que respondeu em momento anterior, em que, ao responder sobre se a música contribui para o desenvolvimento da criança, ela mesma fala que a música não contribui de forma significativa.

Acredito que depende da música, pois atualmente é preciso filtrar canções já que, as crianças estão escutando músicas de adultos, e muitas das que são feitas para as crianças são apenas um 'passa tempo'. Não que elas não possam ouvir músicas infantis por prazer, mas para a educação das crianças, penso que não contribuem de forma significativa. (P2, 2018).

De acordo com Queiroz (2000), assim como toda obra de arte tem conteúdo, a música também tem, porém é necessário distinguir alguns critérios para reconhecer um bom conteúdo musical e com isso, a música tem a capacidade de oportunizar a satisfação sensorial, ou seja, impressionar uma pessoa e fazer com que ela relaxe.

Analisando as respostas das professoras, traz-se a reflexão de Lino (2009, p. 78), sobre o espaço que pode ser "[...] um lugar privilegiado para o desenvolvimento da atividade musical, já que a criança se expressa espontaneamente sonora e corporalmente, a educação Saberes Pedagógicos, Criciúma, v. 4, nº1, janeiro/abril 2020.- Curso de Pedagogia- UNESC 
infantil é o momento mais indicado para se iniciar o trabalho sistemático com música."

No entanto, é preciso tomar alguns cuidados, como por exemplo, o que explica Queiroz (2000, p. 157), quando diz que se faz necessário escolher um local, que seja definido para ouvir a música, e com isso, "é preciso delinear um tempo específico para a audição musical, evitando a tentação sempre presente de misturar a audição com outros afazeres."

A partir da reflexão da citação de Queiroz (2000), percebemos a necessidade de se ter um lugar próprio para a música em sala de aula, assim, como Lino (2009, p. 80), nos fala:

[...] colocar a disposição das crianças um microfone para que elas possam experimentar os efeitos acústicos de sua voz nesse aparelho; planejar um momento diário para a realização da atividade musical; oferecer uma atividade diária de relaxamento e apreciação musical, quando todos os alunos possam ouvir música, deitados no chão de olhos fechados; enfim, criar rotinas na educação infantil, para que a criança possa deixar as suas marcas de música.

Ao refletir sobre se essas professoras utilizam a música de mídia em sala de aula, vemos que algumas professoras ainda estão presas às músicas antigas, porém outras participantes, como, por exemplo, P6, afirmam que usam a música de mídia em sua sala de aula. Mas, no outro lado temos outras professoras, como P2 a qual expõe que a música de mídia, para o seu interesse, não tem relevância, pois não irá fazer com que a criança aprenda.

\section{CONCLUSÃO}

A pesquisa partiu do problema: As professoras da Educação Infantil se utilizam das músicas de mídia em sala de aula? A partir disso, foi elaborado um questionário, para coletar dados referentes ao tema. De acordo com a coleta de dados, foi possível conhecer um pouco sobre o processo atual das práticas que as professoras desenvolvem em sala de aula, envolvendo a música de mídia. Além da pesquisa realizada com as professoras através do questionário, foi preciso se embasar em teóricos que falam sobre este tema tão importante na educação das crianças.

Com relação aos objetivos da pesquisa, estes foram atingidos, pois foi possível analisar se as professoras da Educação Infantil utilizam músicas de mídia em sua sala de aula

Saberes Pedagógicos, Criciúma, v. 4, nº 1, janeiro/abril 2020.- Curso de Pedagogia- UNESC 


\section{SABERES PEDAGÓGICOS}

Revista do Curso de Graduaçūo de Pedagogia - Unesc

ISSN $2526-4559$

bem como compreender a importância da música para o desenvolvimento cognitivo da criança; refletir sobre as músicas de mídia e outros gêneros musicais trabalhados dentro da sala de aula; identificar diferentes possibilidades de trabalhar a música na escola; verificar se as professoras utilizam CDS e DVDS apenas para entretenimento, ou se é proposto cantar com gestos e outras expressões corporais.

Ao longo da pesquisa todos estes objetivos foram alcançados de maneira que o estudo possibilitou algumas reflexões sobre a realidade do tema estudado. A partir do referencial teórico foi possível perceber a importância do professor como mediador nessas práticas e também na seleção de músicas para serem trabalhadas em sala de aula.

Ao finalizar a pesquisa com as professoras, foi possível concluir que algumas participantes utilizam a música para momentos de descontração e para auxiliá-las nos projetos pedagógicos. Elas reconhecem a importância que a música tem na educação dos seus alunos como processo de aprendizagem, porém, algumas consideram que nem todas as práticas estão realmente alcançando o objetivo de aprendizagem, pois cantar ou colocar músicas em rádio ou celular para a criança dançar e apenas descontrair, não irá, de maneira significativa contribuir na formação da criança. Podemos destacar também que o CD e DVD já estão sendo pouco usados em sala de aula e que os meios tecnológicos mais avançados estão mais em uso pelas professoras.

Compreende-se então a importância do professor mediar essas músicas em sala de aula e não apenas utilizar como descontração, para sair da rotina. É importante que o professor busque atividades musicais com os seus educandos, de maneira com que eles possam exercer a ação espontânea sobre o som e também que tenham momentos de recepção sensorial, que possam estimular os movimentos e os sentimentos. Proporcionar o contato com materiais musicais simples e complexos para assim desafiar os seus educandos quanto ao seu conhecimento musical.

Não se faz necessário esperar que os educandos aprendam partituras e sejam mestres em música. Mas sim que a criança tenha uma audição consciente, aprenda a ouvir os sons que podem ser ruídos ou não. Também que a música contribua para a percepção da fantasia, da sensação, que a criança tenha o contato físico com o som.

Saberes Pedagógicos, Criciúma, v. 4, nº 1, janeiro/abril 2020.- Curso de Pedagogia- UNESC 


\section{SABERES PEDAGÓGICOS}

Revista do Curso de Graduaçūo de Pedagogia - Unesc

ISSN 2526-4559

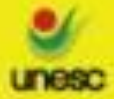

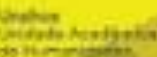

Por fim, podemos dizer que a música é um elemento auxiliador para a formação das pessoas e, nesse sentido, a música de mídia, mediada pelo professor de maneira significativa, pode sim contribuir para aprendizagem do educando, assim como sobre o desenvolvimento da sensibilidade, do senso rítmico, da criatividade, da escuta musical, da expressão corporal entre outros, desde a Educação Infantil.

\section{REFERÊNCIAS}

ANDRADE, Annielly da Silva. A música como instrumento facilitador da aprendizagem na educação infantil. p. 30. 2012. Disponível em:

<http://dspace.bc.uepb.edu.br/jspui/bitstream/123456789/1327/1/PDF\%20-

\%20Annielly\%20da\%20Silva\%20Andrade.pdf>. Acesso em: 10 abr. 2018.

ASSANO, Cristhiane Reis Dias Villela. Um pequeno divertissiment de garrafas, sapatos e cacarecos. In: Garcia Leite Regina. (Org.). Múltiplas linguaguens na escola. Rio de Janeiro: DP\&A, 2000. p 107.

BEYER, Esther Sulzbacherwondracek. O som e a criatividade reflexões sobre experiências musicais. Santa Maria, RS: UFSM, 2005. p 237.

BRASIL. Ministério da Educação. Secretaria de Educação Básica. Diretrizes curriculares nacionais para a educação infantil. Brasília: MEC/SEB, 2010.

CRICIÚMA. Diretrizes curriculares da educação infantil da rede municipal de ensino de Criciúma: a criança como protagonista da aprendizagem/Criciúma, SC: Prefeitura Municipal. Secretaria de Educação, 2016. 257 p.

KUHLMANN, Moysés Jr; FERNANDES, Rogério. Sentidos da infância. In: MENDES, Luciano Faria Filho. (Org). A infância e sua educação - materiais, práticas e representações (Portugal e Brasil). Belo Horizonte, 2004. p 232.

LAZZARIN, Luíz Fernando. A compreensão do significado estético em educação musical. In: BEYER, Esther Sulzbacherwondracek. (Org).O som e a criatividade reflexões sobre experiências musicais. Santa Maria, RS: UFSM, 2005. p 237.

LINO, Dulcimarta, Lemos. Música é...Cantar, dançar... e brincar! Ah, tocar também! In: CUNHA, Susana Rangel Vieira da. (Org).Cor, som e movimento: a expressão plástica, musical e dramática no cotidiano da criança. 7. Ed Porto Alegre: Mediação, 2009.p 190. 
A paisagem sonora como desafio para a criação musical. In: BEYER, Esther Sulzbacherwondracek. (Org). O som e a criatividade reflexões sobre experiências musicais. Santa Maria, RS: UFSM, 2005. p 237.

MOREIRA, Ana Claudia; SANTOS, Halinna e COELHO, Irene S;. A música na sala de aula - A música como recurso didático. UnisantaHumanitas, nº 1, Vol. 3, p. 41-61. 2014.

Disponível em: <http://periodicos.unisanta.br/index.php/hum/article/view/273/274> Acesso em: 01 Out. 2018.

QUEIROZ, Gregório J. Pereira de. A música compõe o homem, o homem compõe a música. São Paulo: Cultrix, 2000. p 182.

SANTOS, Maria de Fátima Ribeiro dos; SANTOS, Saulo Ribeiro dos. Metodologia da pesquisa em educação. São Luís: UemaNet, 2010. p 67. 